\title{
Through the Looking Glass: In Vitro Models for Inhalation Toxicology and Interindividual Variability in the Airway
}

\author{
Samantha C. Faber ${ }^{1}$ and Shaun D. McCullough ${ }^{2}$
}

\begin{abstract}
With 7 million deaths reported annually from air pollution alone, it is evident that adverse effects of inhaled toxicant exposures remain a major public health concern in the 21st century. Assessment and characterization of the impacts of air pollutants on human health stems from epidemiological and clinical studies, which have linked both outdoor and indoor air contaminant exposure to adverse pulmonary and cardiovascular health outcomes. Studies in animal models support epidemiological findings and have been critical in identifying systemic effects of environmental chemicals on cognitive abilities, liver disease, and metabolic dysfunction following inhalation exposure. Likewise, traditional monoculture systems have aided in identifying biomarkers of susceptibility to inhaled toxicants and served as a screening platform for safety assessment of pulmonary toxicants. Despite their contributions, in vivo and classic in vitro models have not been able to accurately represent the heterogeneity of the human population and account for interindividual variability in response to inhaled toxicants and susceptibility to the adverse health effects. Development of new technologies that can investigate genetic predisposition, are cost and time efficient, and are ethically sound, will enhance elucidation of mechanisms of inhalation toxicity, and aid in the development of novel pharmaceuticals and/or safety evaluation. This review will describe the classic and novel cell-based inhalation toxicity models and how these emerging technologies can be incorporated into regulatory or nonregulatory testing to address interindividual variability and improve overall human health.
\end{abstract}

Keywords: inhalation, interindividual variability, in vitro, lung, three-dimensional model, toxicity

\section{Introduction}

$\mathbf{E}$ XPOSURE TO INHALED TOXICANTS occurs ubiquitously from a range of sources, including air pollution, industrial and commercial chemicals, and consumer products. While some of these chemical exposures can be relatively benign, others can exhibit acute or chronic toxic effects both within the exposed lung tissue and throughout the body. Despite a small number of inhaled toxicants that have been reasonably well studied using traditional methods, the vast majority of inhaled chemicals remain to be examined with appreciable depth to reliably assess their impact on human health and develop and implement risk assessment strategies that effectively address their effects on susceptible populations. Human exposure data are the "gold standard" for understanding the effects of inhaled toxicants on health outcomes; however, in vivo human (controlled human exposure and epidemiology) studies can only be used to collect data for a small fraction of inhaled chemicals due to safety/ethical precautions, high cost, long study duration, and low resolution with respect to the effects of exposures at the cellular and molecular level. In vivo animal exposure models have been used to fill data gaps, but the animals used in these studies have fundamental anatomical, physiological, and biochemical differences compared with their human counterparts, and there has been a growing moral and ethical movement toward the use of in vitro and computational methods when reasonable. $^{1-4}$

Traditional monoculture models have been used to identify signaling molecules involved in the mechanisms and preclinical candidates for pulmonary toxicity; however, this model system ultimately lacks key features of the human airway

\footnotetext{
${ }^{1}$ Curriculum in Toxicology, University of North Carolina at Chapel Hill, Chapel Hill, North Carolina.

${ }^{2}$ National Health and Environmental Effects Research Laboratory, US Environmental Protection Agency, Research Triangle Park, North Carolina.
} 
microenvironment that are essential to accurately recapitulate human inhalation toxicity. Considering little is known regarding the degree of variability within a heterogeneous population exposed to complex mixtures of inhalation toxicants, there lies a significant disconnect between classic in vitro models and population-level risk assessment. In some cases, the use of physiologically relevant in vitro models (e.g., differentiated human primary cells) has provided insight into the molecular mechanisms underlying exposure effects and interindividual variability in susceptibility that had not been characterized despite decades of in vivo human, animal, and traditional in vitro studies.,

In this study, we discuss the use of a wide range of in vitro cell-based models in inhalation toxicology and the potential for these models to provide insight into the mechanisms of interindividual variability in inhaled toxicant exposure effects and susceptibility.

\section{In Vitro Cell-Based Models for the Human Airway}

A model system must meet both scientific and practical criteria to be considered ideal for inhalation toxicology. Model systems should be reasonably physiologically relevant and be amenable to use in experimental settings that recapitulate real-world exposure scenarios. They should also be cost and time effective, and facilitate the exploration of key events in exposure-mediated toxicity at the desired level (molecular, cellular, organ, or organism). Both in vivo animal and in vitro models are commonly used in inhalation toxicology, and both have advantages and limitations with respect to how faithfully they represent human biology and pathophysiology.

\section{Monocultures: the traditional in vitro model for inhalation toxicology}

Two-dimensional (2D) single-cell-type cultures ("monocultures") have been widely used as in vitro models of the human airway for decades. The airway epithelium is at the interface, where inhaled chemicals interact with lung tissue. In addition to serving as the initial barrier and first line of defense from inhaled chemicals (as reviewed by Refs. ${ }^{7-10}$ ), the airway epithelium serves as a proinflammatory signaling platform to recruit and activate immune cells (e.g., neutrophils and macrophages) following toxic chemical exposure. As a result, cell lines derived from the airway epithelium, such as 16HBE14o- (16HBE), ${ }^{11,12}$ BEAS2-B, ${ }^{13}$ and A549, ${ }^{14}$ have been and still are the most popular monocultures used in inhalation toxicology.

These traditional in vitro models provided the foundation for understanding the role of epithelial cells in the effects of inhaled toxicants, as well as the molecular mechanisms responsible for the induction of key toxicological phenomena, such as oxidative stress ${ }^{15-17}$ and proinflammatory signaling, ${ }^{18-20}$ among others. While the A549 and Calu-3 cell lines were derived from a lung carcinoma and lung adenocarcinoma, respectively, and readily form tumors in mouse xenograft models,${ }^{14}$ the BEAS-2B, 16HBE, and HBEC3-KT cell lines were derived from artificially immortalized normal bronchial epithelial cells and are nontumorigenic. ${ }^{11,21,22}$ Basic characteristics of several airway epithelial cell lines are summarized in Table 1.

Cell-line based monoculture models are readily accessible, straightforward, and practical; however, these systems lack architectural support and heterogeneity of lung cell type characteristic of the lung in vivo, which makes it difficult to recapitulate physiological and pathophysiological functions in vitro. While still relatively limited due to cost and accessibility, the use of primary airway epithelial cells has increased in recent years, due in part to the value of validating cell linebased findings and their increased availability through several commercial providers. The tracheobronchial epithelium contains several distinct lung progenitor cells capable of selfrenewal and differentiation, including, basal cells, pulmonary neuroendocrine cells, alveolar epithelial cells type 2 , and bronchioalveolar stem cells.

Most airway epithelial cell lines are not known to undergo differentiation (Table 1); however, when grown at air-liquid interface (ALI) in the presence of the appropriate medium, primary airway epithelial cells will polarize and form a pseudostratified epithelium composed of basal, ciliated, and goblet cells that closely resemble the human in vivo airway epithelium. ${ }^{23-27}$ Fully differentiated culture exhibit tight junctions, beating cilia, and secrete mucin and protective mediators (e.g., antimicrobial peptides and proinflammatory cytokines). The resulting differentiated model is highly representative of the airway epithelial structure and function in vivo. ${ }^{23}$ The advent of ALI has led to key advances in the characterization of cell biology of the respiratory epithelium, study of infection of the respiratory epithelium, testing of drug formulations for inhalation delivery, and inhalation toxicity testing. ${ }^{28-32}$

Primary airway epithelial cell models also facilitate the identification of functional differences between epithelial cells from "healthy" donors, or those with respiratory disease (e.g., asthma or cystic fibrosis), at the cellular level. For example, ALI culture of cells from healthy and asthmatic children revealed differences in proinflammatory and epithelial remodeling factors ${ }^{33}$ and primary ALI cultures exposed to pathogens or air pollutants demonstrated intrinsic phenotypic differences between an asthmatic epithelium and healthy epithelium inflammatory response. ${ }^{34}$

Despite significant impacts to the field, in vitro inhalation toxicity research is moving away from monoculture models focused on the impacts of inhaled toxicants to the airway epithelium, and toward more physiologically relevant threedimensional (3D) models in the hope of increasing our understanding of lung physiology and toxicity and improve human health.

\section{$3 D$ in vitro models}

Two-dimensional monoculture models have been the foundation of in vitro inhalation toxicology research for decades; however, these traditional models are unable to account for the contributions of critical cell types within the airway microenvironment, such as fibroblasts, endothelial cells, and immune cells, among others, to exposure outcomes. In the absence of these other cell types, monoculture models are unable to incorporate important biological context that is provided by the airway microenvironment, which influences the expression of soluble factors, gene regulation, and the response to therapeutic agents. ${ }^{35,36}$ Thus, to achieve greater physiological relevance and gain better insight into the role of the airway microenvironment in the response to inhaled chemicals, other relevant airway cell types must be incorporated into 3D and organotypic in vitro models (Fig. 1).

These models have seen limited use in inhalation toxicology, but their development and integration is still in its 


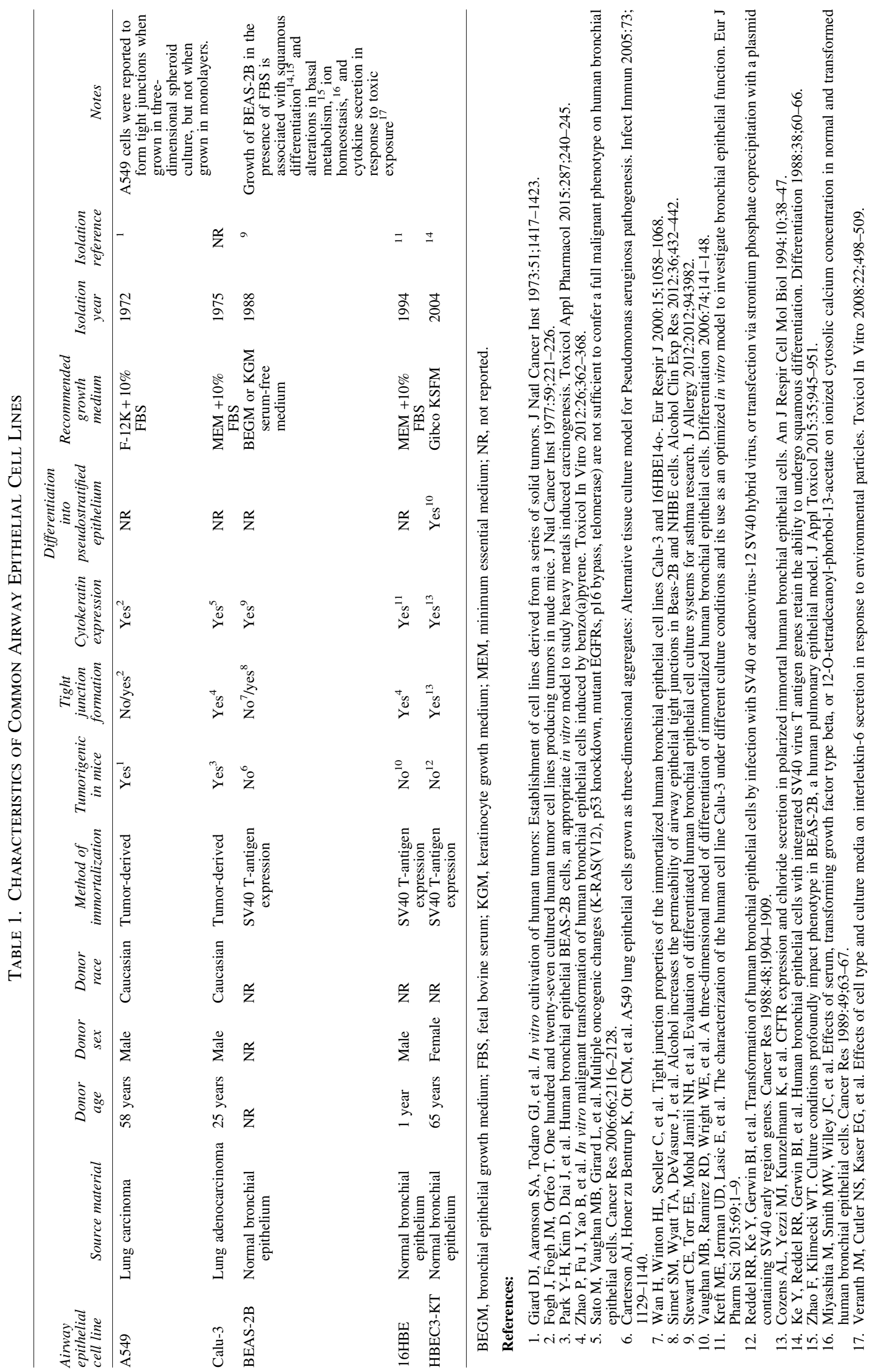


A Two-dimensional monoculture

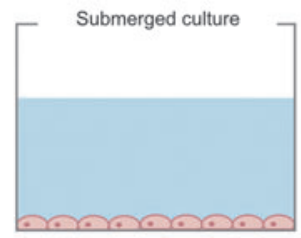

Glass or plastic

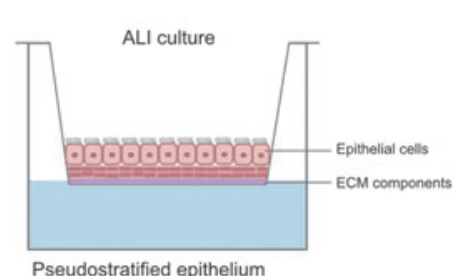

Pseudostratified epithelium
Pros

- Ease of cultivation

- Cost

- Time

- Cell-specific analysis

- High-throughput

B Organotypic Culture
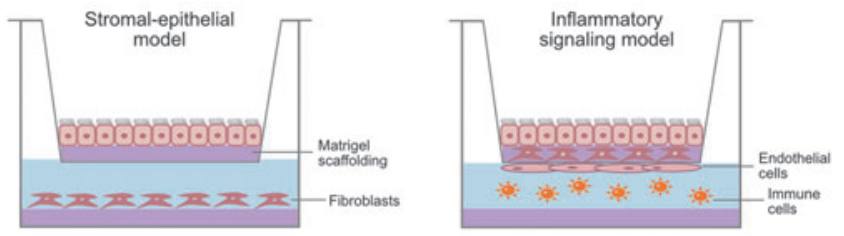

- Cost-effective
- Cellular interactions
- Cell-specific analysis
- High-throughput

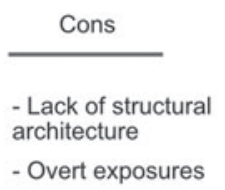

- Overt exposures

\author{
- Lack of seeding \\ standardization \\ - Cell types with \\ different media \\ components \\ - Changeable \\ scaffolding materials
}

\section{Spheroid Culture}
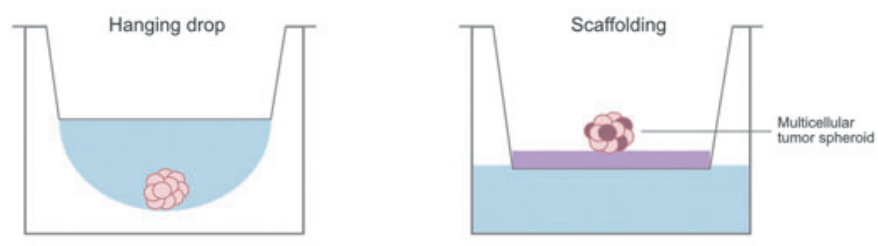

- Recapitulates 3D tumor environment

- Cellular interactions

- Lack of seeding standardization

- Cell-specific analysis

- Lack of spheroid size uniformity

- High-throughput

- Changeable scaffolding materials

- No cell-specific analysis

Organoid Culture
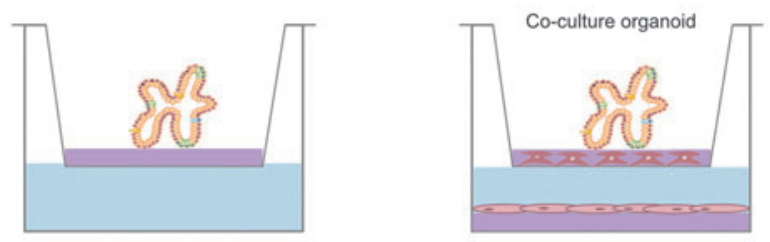

- Recapitulates structural architecture

- Lack of seeding standardization

- Cellular interactions

- Lack of organoid size uniformity

- Cell-specific analysis

- Changeable scaffolding

- High-throughput materials

- No cell-specific analysis

E Microfluidic and Microfabricated Culture

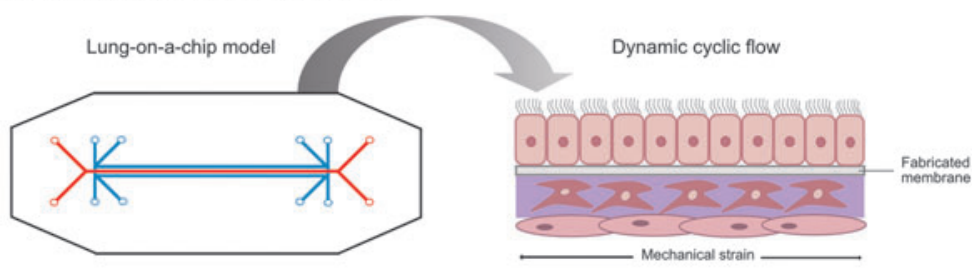

- Recapitulates
physiological
breathing motions
- Cellular interactions
- Nutrient/waste
input/output
- Recapitulates organ-
level functions

- Small sample size

- Different cell type media components

- Expensive

- Not high-throughput

- No cell-specific

analysis

FIG. 1. Cell-based in vitro lung models for the study of inhalation toxicity. Visual representation of monoculture and threedimensional in vitro models and the pros and cons of each model system for the study of inhalation toxicity. (A) Twodimensional monoculture, (B) organotypic culture, (C) spheroid culture, (D) organoid culture, and (E) microfluidic and microfabricated device culture. ECM, extracellular matrix.

infancy. The following sections will discuss the benefits, limitations, and potential impact of these new in vitro models in inhalation toxicology.

Organotypic models. Building upon the widespread use of monoculture platforms for respiratory toxicant screening, drug discovery, and characterization of signaling pathways, organotypic models have been successful in their ability to model 3D lung microenvironments using commercially available cell culture materials in a co- or multicultural system. Organotypic models are comprised of two, or more, individual cell types cultured together and often involve an extracellular matrix (ECM; e.g., Matrigel ${ }^{\circledR}$ or collagen) scaffold. Porous/ permeable membranes (i.e., Transwell ${ }^{\circledR}$ or Millicell ${ }^{\circledR}$ ) can also be integrated into organotypic models to allow for the disarticulation of the individual cell types for cell type-specific analysis. Organotypic models can be developed with commercially available tissue culture materials, and are amenable to different experimental designs and modeling of complex pulmonary toxicant responses, including inflammation, oxidative stress, myofibroblast formation, transepithelial migration, and invasion. Notably, vital cell-cell communication between two 
distinct lung cell types and cell-specific analysis (e.g., gene transcription or protein expression) can be performed following either submerged or ALI exposure.

The incorporation of ECM proteins or hydrogel scaffolding within the organotypic model can serve as a template to regulate cellular proliferation, differentiation, and function in a manner similar to that found in vivo. Scaffolding can be comprised of biological materials (e.g., collagen, fibrin, hyaluronic acid, chitosan, alginate, silk fibrils, or Matrigel) or synthetic polymers (e.g., polylactic acid units or enzyme-cleavable polypeptide sequences in polymer network backbones); however, the use of Matrigel is often considered the gold standard due to its similarity to the in vivo environment. ${ }^{37,38}$ While the inclusion of ECM alone is sufficient to augment the phenotypic response of airway epithelial cells, ECM hydrogels can also be used as a substrate for embedding stromal cells. ${ }^{39-42}$

The embedding of additional lung cell types (e.g., fibroblasts) within biological scaffolding (e.g., collagen hydrogels) further recapitulates the in vivo lung microenvironment in vitro, and enhances physiological relevance of organotypic models. ${ }^{43}$ The ALI bronchial epithelial model constructed by Marrazo et al. exhibited tight junctions, epithelial polarity, and expression of a continuous laminin layer, which confirmed this model as a viable approach to study transepithelial invasion and migration. ${ }^{43}$ Primary asthmatic bronchial epithelial cells have also been shown to differentially regulate human lung fibroblast expression of ECM components (i.e., COL3A1, COL1A1, and HAS2) and myofibroblast transition within the context of an organotypic model with embedded fibroblast scaffolding. ${ }^{44,45}$

Branching morphogenesis during lung development with apical and distal airway epithelial cell markers can also be modeled in this system by reconstituting the basement membrane with cocultured human lung fetal fibroblasts and human bronchial epithelial cells. ${ }^{39}$ The incorporation of fibroblasts also alters the basal transcriptome of adjacent epithelial cells in a manner that supports multipotency and differentiation in vitro. ${ }^{46}$

Organotypic models also mimic epithelial barrier properties and changes in cytotoxic and proinflammatory effects after environmental toxicant exposure similar to those observed in vivo. ${ }^{47-50}$ Chemical challenge to an alveolar-capillary organotypic model comprised of a triculture of epithelial cells, macrophages, and endothelial cells, demonstrated expression of tight and adherent junction formation proteins (i.e., occludin, E-cadherin, and VE-cadherin) and presence of desmosomes, indicating an acceptable epithelial barrier for the study of nanoparticle translocation and internalization. ${ }^{47}$ A similar study identified cell type-specific expression of proinflammatory markers (tumor necrosis factor- $\alpha$ [TNF- $\alpha$ ], interleukin [IL]-8, and IL- $1 \beta$ ) and oxidative stress kinetics within the human monocytic cell line THP-1, Calu-3, and HPMEC-ST1.6R (human pulmonary endothelial cells) following coculture in an organotypic model, highlighting the capacity of organotypic models for delineating complex pathways in individual cell types. ${ }^{51-53}$

Organotypic models are cost effective, recapitulate in vivo cellular interactions and inhalation toxicity endpoints, and adaptable to various exposure scenarios for high-throughput screening. The ease of use and cost make organotypic models a viable approach for widespread adoption when moving away from monoculture models in inhalation toxicology.
Multicellular spheroids. Multicellular spheroids (MCS) are a well-established 3D in vitro model for lung physiology and avascular tumor growth. MCS have been generated using human embryonic stem cells (hESCs), lung progenitor cells, and primary cells, and were originally developed to recapitulate the functional phenotype of human tumor cells in response to radiotherapy, and have been adapted for experimental cancer research and oncological drug screening as multicellular tumor spheroids (MCTS). ${ }^{54}$ MCTS are characterized by an external proliferating zone, internal quiescent zone with limited distribution of oxygen, nutrients, and metabolites, and a necrotic zone and resemble cellular heterogeneity of solid tumors in vivo. ${ }^{55-}$ ${ }^{58}$ MCTS exhibit oxygen, nutrient, metabolite, and soluble signaling molecule gradients, and develop heterogeneous cell populations within a lung tumor microenvironment. ${ }^{59}$

MCS or MCTS can be generated in a liquid-based format or on scaffolds and exhibit well-defined geometry, physiologically relevant cell-cell and cell-ECM interactions, and can be grown to a wide range of dimensions. ${ }^{60,61}$ Culturing on scaffolds within Transwell inserts allows MCS to be amenable to ALI culture conditions and modeling of aerosol-specific exposures. Low adhesion plates/coatings are used to promote self-aggregation of cells into spheroids with well-defined geometry using wells with round, tapered bottoms, which position a single spheroid per well, allowing for formation, propagation, analysis of spheroids within a single plate.

Hanging drop plates (HDP) offer another alternative for the formation of MCS. Cells in media are dispensed into the top of a HDP well and cells are segregated into discrete media droplets formed below the aperture HDP well bottom opening, leading to spheroid formation. ${ }^{42,62,63} \mathrm{HDP}$ allow incorporation of additional cell types, such as fibroblasts, endothelial cells, and immune cells. While they can be studied continuously, further analysis requires transfer to conventional culture plate, therefore limiting the use of HDP spheroids in high-throughput screening approaches.

Incorporation of bioreactors (i.e., spinner flask or microgravity bioreactor) can drive cells to self-aggregate into spheroids under dynamic culture conditions. Bioreactors also allow for large-scale production of MCS and microfluidics for continuous flow of nutrients and excretion of waste products. ${ }^{50,64-67}$ Unfortunately, bioreactors can induce fluidic flow shear stress and uniformity of spheroid size is not well regulated.

Micro- or nanopatterned surfaces can also be used as scaffolds to control cell adhesion and migration to enable spheroid cultures. ${ }^{65,68}$ Nanoscale scaffolds are imprinted on flat substrates (e.g., fabrication materials) and cell-specific patterns or adhesive properties can be optimized depending on experimental design. Fabrication platforms can measure physiologically active spheroids for adaptation to highthroughput screening, and enable long-term spheroid cultivation with real-time morphological observations and exposures to chemical stimuli.

Compared with 2D cultures, 3D spheroids more accurately mimic cellular response and growth factor changes relative to natural lung tumor microenvironments. ${ }^{70}$ Spheroids can retain interindividual variability when derived from primary cells and are phenotypically and morphologically stable while retaining viable functions for weeks. ${ }^{71}$ Primary lung biopsies collected from healthy and idiopathic pulmonary fibrosis (IPF) patients were used to generate MCS for screening of novel IPF therapeutic agents in the hope of progressing 
toward personalized and predictive models for assessing antifibrotic therapies. ${ }^{72}$ In addition, circulating tumor cells from patients with small cell lung cancer (SCLC) were isolated to develop patient-specific cell lines that self-aggregated to form spheroids for characterization of metastasis and drug resistance to SCLC therapeutics. ${ }^{73}$ Drug efficacy has also been modeled in a nonsmall cell lung cancer (NSCLC) MCS model using A549 and H358 lung alveolar bronchiole cells. The 3D MCS model was more resistant to the chemotherapeutic paclitaxel, both in submerged and aerosolized particle form, compared with $2 \mathrm{D}$ in vitro lung models. ${ }^{74}$

This is consistent with other MCS models that have demonstrated increased resistance of the 3D MCS model to pulmonary therapeutics relative to classic monoculture systems. ${ }^{73,75}$ Recently, changes in migration, proliferation, and matrix remodeling have been observed using alveolar epithelial cells on microspheres encapsulated with a fibroblast hydrogel for a model of cancer progression and stromal-epithelial tumor microenvironment. ${ }^{76}$ Spheroids have been utilized in a high-throughput 3D lung tumor assay to screen the effects of compounds on cellular proliferation and migration for small molecule therapeutic development; however, limited use of MCS models beyond drug discovery has been seen. ${ }^{70}$ Future research focused on the effects of air pollutants or pulmonary toxicants in multicellular tumor spheroid models can help expand our understanding of chemical sensitization and the effects of inhalation toxicants on susceptible diseased populations.

Organoid models. Lung physiology depends on tissue function derived from the synergistic interaction of multiple cell types distributed and organized within a 3D structure and supported by ECM. Spatial arrangement is crucial for normal cellular interaction and function, and thus organoids serve as an attractive prospect for exploring developmental, disease, and therapeutic biology through the ability to develop multiple cell types and tissue types (i.e., epithelium and mesenchyme), approximate organ-specific cellular organization, and demonstrate levels of native organ function. While the term "organoid" has been used for decades to describe generation of a spheroid following aggregation of differentiated cells that exhibit some tissue-like structures, the modern description refers to stem cell-derived native-like tissue structures of a given organ created by the induction of genetically encoded self-assembly programming. ${ }^{77}$ Similar to processes that regulate organogenesis during embryonic development, cells within organoids undergo self-organization guided by cell-specific adhesion properties and spatially restricted progenitor differentiation. ${ }^{78,79}$

Organoids can be developed from primary cells, immortalized cell lines, and human pluripotent stem cells (hPSCs). Traditional stem cell monoculture formats are capable of organogenesis when cultured under specific conditions (i.e., $3 \mathrm{D}$ culture or ALI); however, when grown in 2D culture, they do not exhibit the same level of structural organization, maintenance, and repair that occur within the epithelial compartment of the airway in vivo. ${ }^{80,81}$ The biological relevance and potential to advance regenerative medicine has stimulated research into organ development, disease pathology, toxicity, and drug discovery using organoid models. ${ }^{8}$

Similar to spheroids, organoids can be grown in submerged culture or on hydrogel scaffolds within Transwell inserts for ALI exposure and functional differentiation scenarios. Threedimensional organoids can also be supplemented with sup- ported stromal cultures (e.g., fibroblasts, endothelial cells, or smooth muscle cells) to assist in organoid formation by secreting factors essential for self-organization and differentiation. $^{24,82}$ In fact, human bronchial epithelial cells cultivated in the presence of human umbilical vein endothelial cells and stroma recapitulated branching morphogenesis in a novel organoid model. ${ }^{83}$ The addition of media components necessary for lung epithelial culture, such as epidermal growth factor or retinoid acid, can also play a role in stimulating organoid development and modeling a physiological lung microenvironment. ${ }^{84-86}$ When cultured under appropriate ALI conditions, airway basal epithelial cells self-organize into tracheospheres or bronchospheres, whereas primary alveolar cells become alveolospheres; however, it remains to be determined whether airway-derived organoids contain normal basal cells or multipotent committed progenitor cells. ${ }^{24,87}$

Organoids have been used to model human interindividualvariability, ${ }^{88-90}$ although the use of lung organoids for the assessment of heterogeneous human response is only in its beginnings; however, patient-specific intestinal organoids derived from hESCs and induced pluripotent stem cells (iPSCs) have been used to model patient-specific cystic fibrosis and development of novel therapeutic strategies. ${ }^{91-94}$

Recently, lung organoids have been obtained from human iPSCs and differentiated into anterior foregut spheroids and alveolar organoids. ${ }^{81,95-98}$ Moreover, generation of lung bud organoids (LBO) from human iPSCs containing mesoderm and pulmonary endoderm and developed structural features of a branching airway as well as early alveolar structures, providing an avenue to investigate patient-specific pulmonary response following exposure to respiratory insults. Similar to what is observed in small airway obstruction and bronchiolitis in infants, infection of LBO by respiratory syncytial virus led to swelling, detachment, and shedding of infected cells into the organoid lumens. ${ }^{98}$

A self-assembled human lung tissue for disease modeling and drug discovery for lung diseases characterized by progressive and irreversible scarring, was also derived from hESCs. Single-cell-type mesenchymal organoids treated with transforming growth factor- $\beta 1$ recapitulated morphological scarring characteristic of IPF. ${ }^{99}$ Although this model is limited by a single-cell type, future adaptations that include multiple cell types for modeling of self-assembly and cellcell interactions will enhance the usefulness of this organoid model for lung physiological and toxicological analysis and development of targeted therapies.

Generation of a cystic fibrosis patient-specific airway epithelium lung organoids has also provided a platform for screening pulmonary drug therapies; however, partial loss of cellular physiological function requires additional research into this model before it can be implemented for drug discovery. ${ }^{100}$ Organoids have begun to be adapted for use in high-throughput screening 3D culture systems of airway epithelial morphogenesis, and cytokines and mechanistic pathways involved in lung inflammation have been identified. ${ }^{101}$ Despite limited use of this model for screening of environmental air pollutants, the success of organoids in the field of pulmonary drug discovery suggests similar prowess for future inhalation toxicity assessments.

Microfluidic and microfabricated models. The lung-on-achip (LOC) models have been developed to recapitulate 
both the 3D architecture and mechanical and shear stresses associated with the flow dynamics that result from cyclical breathing. To incorporate greater physiological relevance in in vitro platform, these models utilize microfluidic perfusion systems (i.e., microchips) to mimic the cellular microenvironments within the lung with high spatiotemporal precision. ${ }^{102,103}$ They also recapitulate cell-cell, cell-ECM, and cell-tissue mechanical and biochemical signals.

LOC models are constructed around thin, flexible, porous membranes that facilitate the incorporation of microcompartments for cell growth and fluid/air circulation within the microchips. ${ }^{104-107}$ Classically, human lung epithelial cells are adhered to one side of the ECM-coated membrane, while the opposing side is seeded with human pulmonary vascular endothelial cells to resemble the in vivo airway. ${ }^{102,108}$ Additional cell types can also be added, such as fibroblasts or immune cells, to more closely resemble the heterogeneity of pulmonary parenchymal microenvironment.

The ability to manipulate cyclic flow allows alterations in elastic deformation of the walls of the microchannel chamber separating the epithelium from the endothelium. Cyclic strain can be simulated using biologically inspired actuation mechanisms (i.e., microdiaphragm) to alter intrapleural pressure and simulate cellular-level lung injury under flow conditions that have been implicated in various pulmonary diseases. ${ }^{109}$ Tension and elastic recoil of the membrane and adherent tissue layers allow the epithelium and closely apposed endothelium to stretch and relax, thereby recapitulating the dynamic mechanical distortion of the epithelium-endothelium interface caused by normal breathing movements. ${ }^{109-111}$

Coordination with bioreactor devices allows close monitoring and control of experimental conditions, such as $\mathrm{pH}$, temperature, pressure, nutrients, and waste. Long-term in vitro growth ( $>2$ weeks cell viability) and propagation of diverse lung cell types create a microenvironment in which cells can differentiate at ALI and receive cell-cell signals that closely reflect protein expression profiles similar to those observed in whole organ systems. ${ }^{102,112}$ The addition of ALI culture conditions to LOC platforms has been shown to induce differentiation of epithelial cells seeded within the chip similar to what has been observed following ALI culture in previously described in vitro models.

The goal of an in vitro model is to reproduce key features of in vivo biology and exposure outcomes. Huh et al. demonstrated that the LOC can recapitulate pulmonary inflammation in response to chemical or toxicant challenge similar to in vivo. ${ }^{10,112}$ The addition of TNF- $\alpha$ to the epithelial compartment of the LOC system resulted in neutrophil recruitment from microvasculature to the alveolar compartment and increased generation of reactive oxygen species, two hallmarks of microbial-induced lung inflammation in vivo. The addition of other proinflammatory cytokines (i.e., IL-8, IL-13, or IL-2) in LOC systems, was also shown to recapitulate the respiratory pathophysiological responses of asthma, including cytokine hypersecretion, goblet cell hyperplasia, and decreased ciliary beat frequency. ${ }^{108,112,113}$

Biomimetic microdevices modeling pulmonary edema have also shown that the addition of mechanical forces associated with physiological breathing motions play a crucial role in the development of increased vascular leakage. ${ }^{112} \mathrm{~A}$ recent microfluidic organ-on-a-chip model of NSCLC has demonstrated the ability to recapitulate cancer growth, tumor dormancy, and re- sponse to tyrosine kinase inhibitor therapy. ${ }^{114}$ In fact, the greatest advantage of microfluidic models lies in the ability to assert differential mechanical strain on an organ system, and in terms of the LOC models, has been shown to influence metabolic activity, cytokine secretion, oxidative stress, and overall transepithelial permeability properties. ${ }^{109,112}$

Microfabricated lung models that do not employ microfluidics have also been developed, which integrate a collagenembedded stromal layer as a support for the epithelial layer. Barkal et al., utilized microfabrication techniques to model human pulmonary response to fungal pathogens, and demonstrated that direct infection of the bronchial airway model induces an inflammatory cytokine response and leukocyte recruitment. ${ }^{115}$

Patient-normalized comparison of biological responses in combination with chip models provides a method for validating interindividual variability in vitro. Lung cells sourced from the same individual (healthy and pre-existing condition cell types) can be used to uncover minute phenotypic differences often masked in clinical studies, such as the heterogeneous effect on ciliary beat frequency across the epithelium, following exposure to pulmonary toxicants or therapeutics. ${ }^{116}$ Utilizing this approach, differential expression of surfactant $\mathrm{D}$ within the airways of asthmatics and healthy donors was quantified, and implies an increase in susceptibility to infection and altered inflammatory response in asthmatics compared with healthy patients. ${ }^{117}$

LOC models have also been used to investigate the effects of environmental inhalation toxicants on human health and susceptible populations. Utilizing chronic obstructive pulmonary disease (COPD) and healthy primary cells from a single donor, a small airway-on-a-chip device simulated a smokeinduced pathology through connection to an instrument that breathes whole cigarettes in/out of the system. ${ }^{113}$ LOC breathing models have also been used to study the effects of toxicity following exposure to silica nanoparticles and reproduce drug toxicity-induced pulmonary edema and identify key proinflammatory cytokines altered following physiological breathing motions. ${ }^{110,112}$ Although relatively new to the field of inhalation toxicity, LOCs have the potential to model physiological breathing motions as well as waste and nutrient fluid flow, which provide researchers with a powerful tool for in vitro inhalation toxicity testing.

\section{Modeling interindividual variability in pulmonary disease}

Traditional susceptibility factors are associated with increased risk of adverse effects following inhaled chemical exposures; however, susceptible populations are defined as a result of the average response of the population, which does not imply that all individuals within the population will exhibit exposure effects that are greater, in magnitude or diversity, than their "healthy" counterparts. ${ }^{118-120}$ Furthermore, due to the broad interindividual variability within populations, individuals within the "healthy" population often experience effects of a similar magnitude to individuals in "susceptible" populations. ${ }^{6,121}$ Thus, traditional susceptibility factors alone are not faithful indicators of at-risk individuals. Interindividual variability is readily observed in clinical and epidemiological studies, but these approaches are not well suited to characterize the underlying molecular mechanisms.

These limitations can be overcome by in vitro primary airway epithelial cell models, which have been used to identify 
interindividual differences in surfactant protein production, ${ }^{122}$ expression of metabolic enzymes (e.g., GST1A1, CYP2B6, and CYP2F1), ${ }^{123,124}$ ratio of ciliated and secretory cells, ${ }^{101}$ microRNA expression, ${ }^{125,126}$ and DNA repair ${ }^{127-129}$ in response to pulmonary toxicants. Furthermore, a primary airway epithelial cell model was used to link interindividual variability in pre-exposure epigenetic modification states to exposureinduced gene expression. ${ }^{6}$ While these in vitro models offer the possibility of identifying new biomarkers of susceptibility, they must be used carefully to avoid limitations in experimental reproducibility that can result from differences in lung tissue preparations, storage/transfer conditions, and disease state of donor tissues. ${ }^{130}$

The potential of hESCs and iPSCs to differentiate into diverse cell types provides an exciting tool to model interindividual variability through the ability to study different steps of lung development, unlimited supply of cells, and the possibility of genetic modifications (Fig. 2). Moreover, while primary cells are limited by number of replicative events, stem cells can proliferate indefinitely. hESCs have the ability to differentiate into all specialized cell types (i.e., lung progenitors, mature airway, alveolar cells, and organized airway epithelium) and can potentially be used in matched donor experiments to model interindividual variability with patientspecific genotype and phenotypes.

Likewise, iPSCs can be programmed with transcription factors to differentiate into various cell types to complement $3 \mathrm{D}$ in vitro lung models. iPSCs maintain characteristics of their donor, and iPSC panels/libraries could be used to construct models to study interindividual variability in the human airway. ${ }^{131}$ For example, a diverse, comprehensive, and fully characterized library of sickle-cell disease-specific iPSCs derived from ethnically diverse patients with various polymorphisms has been developed to design patient-specific therapeutics for this highly phenotypically variable disorder. ${ }^{132}$ Several groups have generated lung and disease-expressing
FIG. 2. Generation of specialized patient-specific cells for use in inhalation toxicity testing. Primary airway epithelial cells, hESCs, and iPSCs are generated from a specific donor through distinct culture methods. Each cell type undergoes differentiation to become a specialized patient-specific airway epithelial cell for the use in interindividual screening and inhalation toxicity assessment. hESCs, human embryonic stem cells; iPSCs, induced pluripotent stem cells.

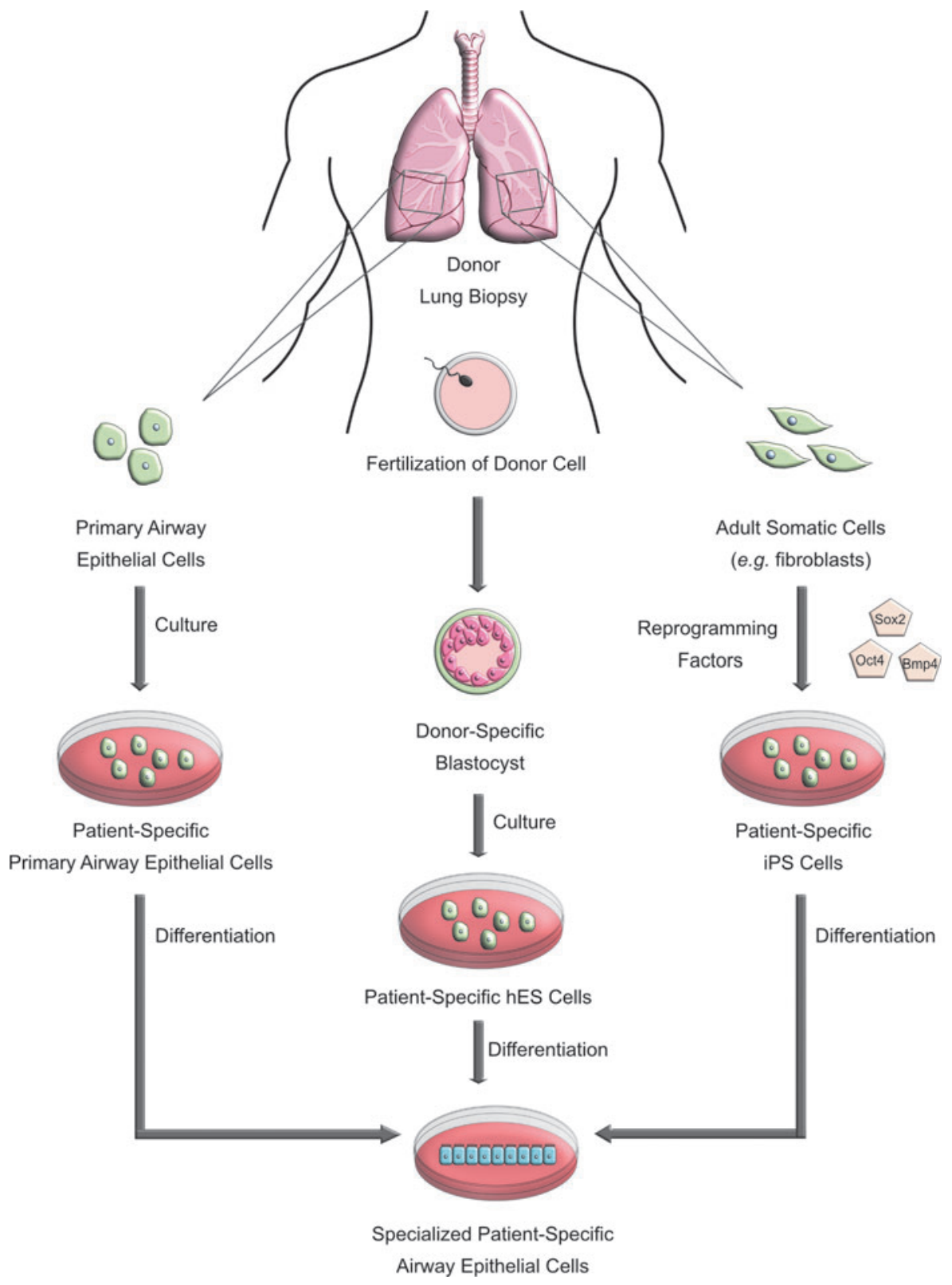


airway epithelial cells from hPSCs as monolayers or spheres ${ }^{133-136}$ and iPSCs are a suitable tool for phenocopying core disease features of COPD, bronchopulmonary dysplasia, and IPF, as well as screening therapeutic agents. ${ }^{137}$ iPSCderived airway epithelial models can also be genetically manipulated to investigate ablation of genes involved in lung development or homeostasis through homologous recombination with the CRISPR/Cas9-mediated system, enabling deletion, insertion, or edits of the genome of any iPSC line for highthroughput screening of a wide range of exposures in genotypically and phenotypically diverse models. ${ }^{138-141}$

In the case of IPF, where primary cells do not expand efficiently in vitro, the use of iPSC-derived IPF cells would be useful for high-throughput small molecule screening for IPF therapeutics across a wide range of susceptibility. ${ }^{98,134}$ Despite its potential, iPSC technology still has to overcome several limitations, such as standardization of culture conditions and reprogramming factors, high costs of growth factors and media, and genetic instability when cultured in stressful conditions, ${ }^{25,142,143}$ before widespread adoption in inhalation toxicology.

\section{Considerations and Challenges for the Use of 3D Models in Safety Evaluation and Drug Development}

In vitro models are valuable tools for chemical screening and to collect cellular and molecular data to provide mechanistic insight and biological plausibility for observations made in in vivo models. ${ }^{144}$ Validity of the model should be demonstrated (robustness, reproducibility, predictive value) to be able to incorporate into an industrial or regulatory setting. ${ }^{145}$ Implementation of new in vitro platforms for screening and in vitro to in vivo extrapolation will also require the establishment of a "gold standard" by which models aim to recapitulate key physiological measurements for validation and acceptance as a reproducible model for human pulmonary physiology and toxicology. Establishment of threshold values for key physiological features of normal lung function, including presence of tight junctions, proinflammatory and oxidative stress gene expression, representation of specific cell types, will be required to ascertain efficacy of models for hazard assessment purposes.

Despite the technological leaps of novel 3D in vitro models and their progress toward providing a biologically representative cellular organization, one of the outstanding challenges of these platforms before their use for hazard assessment will be to delineate what constitute relevant exposure scenarios.

Standardization of universal protocols for these models is lacking in terms of cell type, cell seeding ratios, culture conditions, material composition, and appropriate concentrations of specialized cell types when cultured under ALI conditions for differentiation. For example, synthetic scaffolds are made of a variety of materials with different porosities, permeability, surface chemistries, and mechanical characteristics designed to mimic the lung microenvironment. Scaffolds can be generated using a variety of methods, including 3D printing, electrospinning, gas foaming, fiber meshes and bonding, phase separation, and solution casting, which can also influence physiological and toxicological phenotypes within an experimental setting. Scaffold characteristics and material properties play central roles in regulating cell adhesion, proliferation, activation, and differentiation; however, chemical composition and lot-to-lot variability can negatively impact experimental reproducibility.

Lack of standardization limits the use of spheroids or organoids for the assessment of interindividual variability as well. Challenges to widespread implementation and adaptation to high-throughput screening with organoids for the characterization of pulmonary physiological and toxicological response, include, development/maintenance of organoids, uniform sphere size, low cell seeding density for spheroid formation, precise control of specific ratios of lung cells when in coculture, and lack of a reliable, simple, and universal protocols for cultivation. Furthermore, the presence of ECM or scaffolding can influence variability across study systems, as organoids and spheroids have demonstrated differential morphology when cultured on rigid surfaces versus scaffolds. ${ }^{37,38,146}$ Protocols are being developed to implement uniform sphere sizes, such as the defined size microwell array, to help facilitate assay standardization across the field. ${ }^{147}$

Although hESCs and iPSCs offer unlimited supply of cells and differentiation into patient-specific cell types, several challenges restrict the use of this cell type for widespread incorporation into novel 3D in vitro platforms. Foremost, reprogramming factors and cultivation conditions are not standardized across research groups, leading to variable cellular differentiation composition, proliferation rates, and overall response.

In the case of organoids derived from iPSCs or hESCs, several concerns remain to be addressed before widespread adoption. First, proteomic and epigenomic profiles have not been described and therefore confirmation of the various cell types present or levels of differentiation is relatively unclear. Moreover, little is known regarding whether cells mimic a more adult or fetal phenotype, and, therefore, whether maturation strategies need to be adopted when standardizing protocols is unknown. Lastly, few studies have been carried out to assess whether the addition of cell types (i.e., vasculature or mesenchymal cells) in the 3D organoid culture has an effect on mimicking the in vivo lung phenotype. Similar problems within the rapidly developing field of microfabrication limit implementation of the LOC model for widespread use.

Variation in data analysis and reporting of findings also limit implementation of novel in vitro models for hazard assessment or pharmaceutical screening. The degree of interindividual variability across donors is substantial; however, researchers often employ (1) stringent criteria such that genes of interest must be changed in all donors, (2) filtering systems in which genes of interest are those changed in a particular number of donors, or (3) average expression across donors. ${ }^{148}$ Evidence suggests that large subsets of genes are uniquely regulated within individual donors, whereas small sets of responsive genes are regulated reproducibly by xenobiotic exposures among lung cells across individual donors leading to a very limited number of "hit" genes within an array. ${ }^{142}$ Goyak et al. utilized a computational-based approach that functionally categorized and identified transcriptional patterns across donors in concordance with known mechanisms of action for the toxicant of interest. ${ }^{148}$

Since gene expression does not follow a normal distribution across donors, it is difficult to establish endpoint values that best predict the consequences of toxicant exposures within novel 3D model platforms. ${ }^{149-153}$ However, basic standardization disparities in cell type, cell seeding ratios, 
and culture conditions can result in distinctly different responses to pulmonary toxicants in vitro. For example, HL-60 cells can differentiate into four different cell types (i.e., granulocytes, monocytes, macrophages, and eosinophils) depending on the stimulating agent, ${ }^{86,154}$ and thus cultivation parameters can significantly alter reproducible pulmonary responses.

\section{Conclusions}

Inherent interindividual variability in response to air pollutants and pulmonary function in health and disease has led to the need for improved cell-based in vitro models to assess the effects of inhaled chemicals and identify novel biomarkers of susceptibility. Novel 3D in vitro models offer the advantage of enhanced physiological relevance through incorporation of architectural support (i.e., ECM proteins or scaffolding), cell-cell interactions, and in some instances, biomimetic devices that can recapitulate physiologically breathing motions.

To address differences in response to inhaled toxicants or pharmaceuticals, the true test of these novel models is whether they can reasonably reflect the interindividual variability in exposure response that exists within the human population. Gaining insight into the biological variability in healthy and susceptible populations will eventually help refine risk assessment of air pollutants.

Considering the plethora of potential environmental contaminant exposures, investigation into the molecular mechanisms underlying inherent variability in response will ultimately require both in vitro and in vivo approaches; however, the scope of in vivo studies can be narrowed effectively with data collected from the thoughtful use of in vitro models ranging from cell lines grown in monoculture to LOC microphysiological systems. Furthermore, the in vitro airway models discussed in this study will also play significant roles in characterizing the cellular and molecular mechanisms responsible for the effects of inhaled toxicant exposure, thus increasing the sophistication with which we can approach inhalation toxicology moving forward.

\section{Acknowledgments}

The contents of this article have been reviewed by the Environmental Protection Agency and approved for publication, and do not necessarily represent Agency policy, or does mention of trade names, or commercial products constitute endorsement or recommendations for use.

\section{Author Disclosure Statement}

No competing financial interests exist.

\section{References}

1. Schechtman LM. Implementation of the 3Rs (refinement, reduction, and replacement): Validation and regulatory acceptance considerations for alternative toxicological test methods. ILAR J 2002:43 Suppl;S85-S94.

2. Belliveau ME. The drive for a safer chemicals policy in the United States. New Solut 2011:21;359-386.

3. Impinen A, Nygaard UC, Lodrup Carlsen KC, et al. Prenatal exposure to perfluoralkyl substances (PFASs) associated with respiratory tract infections but not allergy- and asthma-related health outcomes in childhood. Environ Res 2018:160;518-523.
4. Tannenbaum J, Bennett BT. Russell and Burch's 3Rs then and now: The need for clarity in definition and purpose. J Am Assoc Lab Anim Sci 2015:54;120-132.

5. McCullough SD, Duncan KE, Swanton SM, et al. Ozone induces a proinflammatory response in primary human bronchial epithelial cells through mitogen-activated protein kinase activation without nuclear factor- $\kappa \mathrm{B}$ activation. Am J Respir Cell Mol Biol 2014:51;426-435.

6. McCullough SD, On DM, Bowers EC. Using chromatin immunoprecipitation in toxicology: A step-by-step guide to increasing efficiency, reducing variability, and expanding applications. Curr Protoc Toxicol 2017:72;3.14.1-3.14.28.

7. Lopez-Rodriguez JC, Benede S, Barderas R, et al. Airway epithelium plays a leading role in the complex framework underlying respiratory allergy. J Investig Allergol Clin Immunol 2017:27;346-355.

8. Mertens TCJ, Karmouty-Quintana H, Taube C, et al. Use of airway epithelial cell culture to unravel the pathogenesis and study treatment in obstructive airway diseases. Pulm Pharmacol Ther 2017:45;101-113.

9. Shu L, Chan KHK, Zhang G, et al. Shared genetic regulatory networks for cardiovascular disease and type 2 diabetes in multiple populations of diverse ethnicities in the United States. PLoS Genet 2017:13; e1007040.

10. Eapen MS, Myers S, Walters EH, et al. Airway inflammation in chronic obstructive pulmonary disease (COPD): A true paradox. Expert Rev Respir Med 2017:11;827-839.

11. Cozens AL, Yezzi MJ, Kunzelmann K, et al. CFTR expression and chloride secretion in polarized immortal human bronchial epithelial cells. Am J Respir Cell Mol Biol 1994: 10;38-47.

12. Xia B, Yang L-Q, Huang H-Y, et al. Chromium(VI) causes down regulation of biotinidase in human bronchial epithelial cells by modifications of histone acetylation. Toxicol Lett 2011:205;140-145.

13. Albright CD, Jones RT, Hudson EA, et al. Transformed human bronchial epithelial cells (BEAS-2B) alter the growth and morphology of normal human bronchial epithelial cells in vitro. Cell Biol Toxicol 1990:6;379-398.

14. Giard DJ, Aaronson SA, Todaro GJ, et al. In vitro cultivation of human tumors: Establishment of cell lines derived from a series of solid tumors. J Natl Cancer Inst 1973:51; 1417-1423.

15. Wages PA, Silbajoris R, Speen A, et al. Role of $\mathrm{H} 2 \mathrm{O} 2$ in the oxidative effects of zinc exposure in human airway epithelial cells. Redox Biol 2014:3;47-55.

16. Wages PA, Lavrich KS, Zhang Z, et al. Protein sulfenylation: A novel readout of environmental oxidant stress. Chem Res Toxicol 2015:28;2411-2418.

17. Gibbs-Flournoy EA, Simmons SO, Bromberg PA, et al. Monitoring intracellular redox changes in ozone-exposed airway epithelial cells. Environ Health Perspect 2013:121; 312-317.

18. Jaspers I, Flescher E, Chen LC. Respiratory epithelial cells display polarity in their release of the chemokine IL-8 after exposure to ozone. Inflamm Res 1997:46 Suppl 2;S173-S174.

19. Jaspers I, Flescher E, Chen LC. Ozone-induced IL-8 expression and transcription factor binding in respiratory epithelial cells. Am J Physiol 1997:272;L504-L511.

20. Wang H, Duan H, Meng T, et al. Local and systemic inflammation may mediate diesel engine exhaust induced lung function impairment in a Chinese occupational cohort. Toxicol Sci 2017 [Epub ahead of print]; DOI: 10.1093/toxsci/ $\mathrm{kfx} 259$. 
21. Reddel RR, Salghetti SE, Willey JC, et al. Development of tumorigenicity in simian virus 40-immortalized human bronchial epithelial cell lines. Cancer Res 1993:53;985-991.

22. Sato M, Larsen JE, Lee W, et al. Human lung epithelial cells progressed to malignancy through specific oncogenic manipulations. Mol Cancer Res 2013:11;638-650.

23. Dvorak A, Tilley AE, Shaykhiev R, et al. Do airway epithelium air-liquid cultures represent the in vivo airway epithelium transcriptome? Am J Respir Cell Mol Biol 2011: 44;465-473.

24. Rock JR, Onaitis MW, Rawlins EL, et al. Basal cells as stem cells of the mouse trachea and human airway epithelium. Proc Natl Acad Sci U S A 2009:106;12771-12775.

25. Tadokoro T, Wang Y, Barak LS, et al. IL-6/STAT3 promotes regeneration of airway ciliated cells from basal stem cells. Proc Natl Acad Sci U S A 2014:111;E3641-E3649.

26. Polosukhin VV, Cates JM, Lawson WE, et al. Hypoxiainducible factor-1 signalling promotes goblet cell hyperplasia in airway epithelium. J Pathol 2011:224;203-211.

27. Gao X, Bali AS, Randell SH, et al. GRHL2 coordinates regeneration of a polarized mucociliary epithelium from basal stem cells. J Cell Biol 2015:211;669-682.

28. Lewinski NA, Liu NJ, Asimakopoulou A, et al. Air-liquid interface cell exposures to nanoparticle aerosols. Methods Mol Biol 2017:1570;301-313.

29. Polk WW, Sharma M, Sayes CM, et al. Aerosol generation and characterization of multi-walled carbon nanotubes exposed to cells cultured at the air-liquid interface. Part Fibre Toxicol 2016:13;20.

30. Kim JS, Klosener J, Flor S, et al. Toxicity assessment of airdelivered particle-bound polybrominated diphenyl ethers. Toxicology 2014:317;31-39.

31. Kim JS, Peters TM, O'Shaughnessy PT, et al. Validation of an in vitro exposure system for toxicity assessment of airdelivered nanomaterials. Toxicol In Vitro 2013:27;164-173.

32. Ji J, Hedelin A, Malmlof M, et al. Development of combining of human bronchial mucosa models with XposeALI(R) for exposure of air pollution nanoparticles. PLoS One 2017:12; 0170428.

33. Iwanaga K, Elliott MS, Vedal S, et al. Urban particulate matter induces pro-remodeling factors by airway epithelial cells from healthy and asthmatic children. Inhal Toxicol 2013:25;653-660.

34. Hackett T-L, Singhera GK, Shaheen F, et al. Intrinsic phenotypic differences of asthmatic epithelium and its inflammatory responses to respiratory syncytial virus and air pollution. Am J Respir Cell Mol Biol 2011:45;1090-1100.

35. Majety M, Pradel LP, Gies M, et al. Fibroblasts influence survival and therapeutic response in a $3 \mathrm{D}$ co-culture model. PLoS One 2015:10; e0127948.

36. Regier MC, Maccoux LJ, Weinberger EM, et al. Transitions from mono- to co- to tri-culture uniquely affect gene expression in breast cancer, stromal, and immune compartments. Biomed Microdevices 2016:18;70.

37. Zhu J, Marchant RE. Design properties of hydrogel tissueengineering scaffolds. Expert Rev Med Devices 2011:8; 607-626.

38. Tibbitt MW, Anseth KS. Hydrogels as extracellular matrix mimics for 3D cell culture. Biotechnol Bioeng 2009:103; 655-663.

39. Kaisani A, Delgado O, Fasciani G, et al. Branching morphogenesis of immortalized human bronchial epithelial cells in three-dimensional culture. Differentiation 2014: $87 ; 119-126$
40. Jorgens DM, Inman JL, Wojcik M, et al. Deep nuclear invaginations are linked to cytoskeletal filaments-Integrated bioimaging of epithelial cells in 3D culture. J Cell Sci 2017: 130;177-189.

41. Bhat R, Belardi B, Mori H, et al. Nuclear repartitioning of galectin-1 by an extracellular glycan switch regulates mammary morphogenesis. Proc Natl Acad Sci U S A 2016:113; E4820-E4827.

42. Fiore APZP, Spencer VA, Mori H, et al. Laminin-111 and the level of nuclear actin regulate epithelial quiescence via exportin-6. Cell Rep 2017:19;2102-2115.

43. Marrazzo P, Maccari S, Taddei A, et al. 3D reconstruction of the human airway mucosa in vitro as an experimental model to study NTHi infections. PLoS One 2016:11;e0153985.

44. Reeves SR, Kolstad T, Lien T-Y, et al. Fibroblastmyofibroblast transition is differentially regulated by bronchial epithelial cells from asthmatic children. Respir Res 2015:16;21.

45. Reeves SR, Kolstad T, Lien T-Y, et al. Asthmatic airway epithelial cells differentially regulate fibroblast expression of extracellular matrix components. J Allergy Clin Immunol 2014:134;663-670.e1.

46. Delgado O, Kaisani AA, Spinola M, et al. Multipotent capacity of immortalized human bronchial epithelial cells. PLoS One 2011:6; 22023.

47. Paget V, Dekali S, Kortulewski T, et al. Specific uptake and genotoxicity induced by polystyrene nanobeads with distinct surface chemistry on human lung epithelial cells and macrophages. PLoS One 2015:10;e0123297.

48. Pohl C, Hofmann H, Moisch M, et al. Acute cytotoxicity and apoptotic effects after 1-Pam exposure in different cocultures of the proximal and distal respiratory system. J Biotechnol 2010:148;31-37.

49. Papritz M, Pohl C, Wubbeke C, et al. Side-specific effects by cadmium exposure: Apical and basolateral treatment in a coculture model of the blood-air barrier. Toxicol Appl Pharmacol 2010:245;361-369.

50. Emmler J, Hermanns MI, Steinritz D, et al. Assessment of alterations in barrier functionality and induction of proinflammatory and cytotoxic effects after sulfur mustard exposure of an in vitro coculture model of the human alveolo-capillary barrier. Inhal Toxicol 2007:19;657-665.

51. Chandorkar P, Posch W, Zaderer V, et al. Fast-track development of an in vitro 3D lung/immune cell model to study Aspergillus infections. Sci Rep 2017:7;11644.

52. Hanot-Roy M, Tubeuf E, Guilbert A, et al. Oxidative stress pathways involved in cytotoxicity and genotoxicity of titanium dioxide ( $\mathrm{TiO} 2$ ) nanoparticles on cells constitutive of alveolo-capillary barrier in vitro. Toxicol In Vitro 2016:33; 125-135.

53. Tomasek I, Horwell CJ, Damby DE, et al. Combined exposure of diesel exhaust particles and respirable Soufriere Hills volcanic ash causes a (pro-)inflammatory response in an in vitro multicellular epithelial tissue barrier model. Part Fibre Toxicol 2016:13;67.

54. Zanoni M, Piccinini F, Arienti C, et al. 3D tumor spheroid models for in vitro therapeutic screening: A systematic approach to enhance the biological relevance of data obtained. Sci Rep 2016:6;19103.

55. Mueller-Klieser W. Tumor biology and experimental therapeutics. Crit Rev Oncol Hematol 2000:36;123-139.

56. Mueller-Klieser W. Three-dimensional cell cultures: From molecular mechanisms to clinical applications. Am J Physiol 1997:273;C1109-C1123. 
57. Mueller-Klieser W. Multicellular spheroids. A review on cellular aggregates in cancer research. J Cancer Res Clin Oncol 1987:113;101-122.

58. De Sousa E Melo F, Vermeulen L, Fessler E, et al. Cancer heterogeneity-A multifaceted view. EMBO Rep 2013: $14 ; 686-695$.

59. Wenzel C, Riefke B, Grundemann S, et al. 3D high-content screening for the identification of compounds that target cells in dormant tumor spheroid regions. Exp Cell Res 2014:323;131-143.

60. Gong X, Lin C, Cheng J, et al. Generation of multicellular tumor spheroids with microwell-based agarose scaffolds for drug testing. PLoS One 2015:10;e0130348.

61. Vinci M, Gowan S, Boxall F, et al. Advances in establishment and analysis of three-dimensional tumor spheroid-based functional assays for target validation and drug evaluation. BMC Biol 2012:10;29.

62. Amann A, Zwierzina M, Gamerith G, et al. Development of an innovative 3D cell culture system to study tumourStroma interactions in non-small cell lung cancer cells. PLoS One 2014:9; e92511.

63. Bartosh TJ, Ylostalo JH, Mohammadipoor A, et al. Aggregation of human mesenchymal stromal cells (MSCs) into 3D spheroids enhances their antiinflammatory properties. Proc Natl Acad Sci U S A 2010:107;13724-13729.

64. Hu G, Li D. Three-dimensional modeling of transport of nutrients for multicellular tumor spheroid culture in a microchannel. Biomed Microdevices 2007:9;315-323.

65. Wu LY, Di Carlo D, Lee LP. Microfluidic self-assembly of tumor spheroids for anticancer drug discovery. Biomed Microdevices 2008:10;197-202.

66. Cipriano M, Freyer N, Knospel F, et al. Self-assembled 3D spheroids and hollow-fibre bioreactors improve MSCderived hepatocyte-like cell maturation in vitro. Arch Toxicol 2017:91;1815-1832.

67. Massai D, Isu G, Madeddu D, et al. A versatile bioreactor for dynamic suspension cell culture. Application to the culture of cancer cell spheroids. PLoS One 2016:11; e0154610.

68. Jin H-J, Cho Y-H, Gu J-M, et al. A multicellular spheroid formation and extraction chip using removable cell trapping barriers. Lab Chip 2011:11;115-119.

69. Luca AC, Mersch S, Deenen R, et al. Impact of the 3D microenvironment on phenotype, gene expression, and EGFR inhibition of colorectal cancer cell lines. PLoS One 2013:8;e59689.

70. Ekert JE, Johnson K, Strake B, et al. Three-dimensional lung tumor microenvironment modulates therapeutic compound responsiveness in vitro-implication for drug development. PLoS One 2014:9; 92248.

71. Bell CC, Hendriks DFG, Moro SML, et al. Characterization of primary human hepatocyte spheroids as a model system for drug-induced liver injury, liver function and disease. Sci Rep 2016:6;25187.

72. Surolia R, Li FJ, Wang Z, et al. 3D pulmospheres serve as a personalized and predictive multicellular model for assessment of antifibrotic drugs. JCI Insight 2017:2;e91377.

73. Klameth L, Rath B, Hochmaier M, et al. Small cell lung cancer: Model of circulating tumor cell tumorospheres in chemoresistance. Sci Rep 2017:7;5337.

74. Meenach SA, Tsoras AN, McGarry RC, et al. Development of three-dimensional lung multicellular spheroids in air- and liquid-interface culture for the evaluation of anticancer therapeutics. Int J Oncol 2016:48;1701-1709.
75. Manoto SL, Houreld NN, Abrahamse H. Resistance of lung cancer cells grown as multicellular tumour spheroids to zinc sulfophthalocyanine photosensitization. Int $\mathrm{J}$ Mol Sci 2015:16;10185-10200.

76. Lewis KJR, Hall JK, Kiyotake EA, et al. Epithelialmesenchymal crosstalk influences cellular behavior in a 3D alveolus-fibroblast model system. Biomaterials 2018: $155 ; 124-134$.

77. Chatzinikolaidou M. Cell spheroids: The new frontiers in in vitro models for cancer drug validation. Drug Discov Today 2016:21;1553-1560.

78. Miller AJ, Hill DR, Nagy MS, et al. In vitro induction and in vivo engraftment of lung bud tip progenitor cells derived from human pluripotent stem cells. Stem Cell Reports 2018:10;101-119.

79. Nikolic MZ, Caritg O, Jeng Q, et al. Human embryonic lung epithelial tips are multipotent progenitors that can be expanded in vitro as long-term self-renewing organoids. Elife 2017:6; 26575.

80. Nikolic MZ, Rawlins EL. Lung organoids and their use to study cell-cell interaction. Curr Pathobiol Rep 2017: $5 ; 223-231$.

81. Dye BR, Hill DR, Ferguson MAH, et al. In vitro generation of human pluripotent stem cell derived lung organoids. Elife 2015:4;e05098.

82. Butler CR, Hynds RE, Gowers KHC, et al. Rapid expansion of human epithelial stem cells suitable for airway tissue engineering. Am J Respir Crit Care Med 2016:194;156-168.

83. Franzdottir SR, Axelsson IT, Arason AJ, et al. Airway branching morphogenesis in three dimensional culture. Respir Res 2010:11;162.

84. Mondrinos MJ, Koutzaki S, Lelkes PI, et al. A tissueengineered model of fetal distal lung tissue. Am J Physiol Lung Cell Mol Physiol 2007:293;L639-L650.

85. Mondrinos MJ, Jones PL, Finck CM, et al. Engineering de novo assembly of fetal pulmonary organoids. Tissue Eng Part A 2014:20;2892-2907.

86. Fulcher ML, Gabriel S, Burns KA, et al. Well-differentiated human airway epithelial cell cultures. Methods Mol Med 2005:107;183-206.

87. Barkauskas CE, Cronce MJ, Rackley CR, et al. Type 2 alveolar cells are stem cells in adult lung. J Clin Invest 2013: 123;3025-3036.

88. Olivero OA, Ming JM, Das S, et al. Human inter-individual variability in metabolism and genotoxic response to zidovudine. Toxicol Appl Pharmacol 2008:228;158-164.

89. Calderon-Gierszal EL, Prins GS. Directed differentiation of human embryonic stem cells into prostate organoids in vitro and its perturbation by low-dose bisphenol A exposure. PLoS One 2015:10; 0133238.

90. Dedhia PH, Bertaux-Skeirik N, Zavros Y, et al. Organoid models of human gastrointestinal development and disease. Gastroenterology 2016:150;1098-1112.

91. Yui S, Nakamura T, Sato T, et al. Functional engraftment of colon epithelium expanded in vitro from a single adult Lgr5(+) stem cell. Nat Med 2012:18;618-623.

92. Dekkers JF, Van Mourik P, Vonk AM, et al. Potentiator synergy in rectal organoids carrying S1251 N, G551D, or F508del CFTR mutations. J Cyst Fibros 2016:15; 568-578.

93. Vijftigschild LAW, Berkers G, Dekkers JF, et al. beta2Adrenergic receptor agonists activate CFTR in intestinal organoids and subjects with cystic fibrosis. Eur Respir J 2016:48;768-779. 
94. Doeleman WR, Takken T, Bronsveld I, et al. Relationship between lung function and Modified Shuttle Test performance in adult patients with cystic fibrosis: A crosssectional, retrospective study. Physiotherapy 2016:102; 184-188.

95. Yamamoto Y, Gotoh S, Korogi Y, et al. Long-term expansion of alveolar stem cells derived from human iPS cells in organoids. Nat Methods 2017:14;1097-1106.

96. Jacob A, Morley M, Hawkins F, et al. Differentiation of human pluripotent stem cells into functional lung alveolar epithelial cells. Cell Stem Cell 2017:21;472-488.e10.

97. Shafa M, Ionescu LI, Vadivel A, et al. Human induced pluripotent stem cell-derived lung progenitor and alveolar epithelial cells attenuate hyperoxia-induced lung injury. Cytotherapy 2018:20;108-125.

98. Chen Y-W, Huang SX, de Carvalho ALRT, et al. A threedimensional model of human lung development and disease from pluripotent stem cells. Nat Cell Biol 2017:19;542-549.

99. Wilkinson DC, Alva-Ornelas JA, Sucre JMS, et al. Development of a three-dimensional bioengineering technology to generate lung tissue for personalized disease modeling. Stem Cells Transl Med 2017:6;622-633.

100. Mou H, Vinarsky V, Tata PR, et al. Dual SMAD signaling inhibition enables long-term expansion of diverse epithelial basal cells. Cell Stem Cell 2016:19;217-231.

101. Danahay H, Pessotti AD, Coote J, et al. Notch2 is required for inflammatory cytokine-driven goblet cell metaplasia in the lung. Cell Rep 2015:10;239-252.

102. Huh D, Matthews BD, Mammoto A, et al. Reconstituting organ-level lung functions on a chip. Science 2010:328; 1662-1668.

103. Nalayanda DD, Wang Q, Fulton WB, et al. Engineering an artificial alveolar-capillary membrane: A novel continuously perfused model within microchannels. J Pediatr Surg 2010:45;45-51.

104. Whitesides GM, Ostuni E, Takayama S, et al. Soft lithography in biology and biochemistry. Annu Rev Biomed Eng 2001:3;335-373.

105. D'Amico Oblak T, Root P, Spence DM. Fluorescence monitoring of ATP-stimulated, endothelium-derived nitric oxide production in channels of a poly(dimethylsiloxane)-based microfluidic device. Anal Chem 2006:78;3193-3197.

106. Gu W, Zhu X, Futai N, et al. Computerized microfluidic cell culture using elastomeric channels and Braille displays. Proc Natl Acad Sci U S A 2004:101;15861-15866.

107. Song JW, Gu W, Futai N, et al. Computer-controlled microcirculatory support system for endothelial cell culture and shearing. Anal Chem 2005:77;3993-3999.

108. Blume C, Reale R, Held M, et al. Temporal monitoring of differentiated human airway epithelial cells using microfluidics. PLoS One 2015:10;e0139872.

109. Stucki AO, Stucki JD, Hall SRR, et al. A lung-on-a-chip array with an integrated bio-inspired respiration mechanism. Lab Chip 2015:15;1302-1310.

110. Huh DD. A human breathing lung-on-a-chip. Ann Am Thorac Soc 2015:12 Suppl 1;S42-S44.

111. Fishler R, Sznitman J. A microfluidic model of biomimetically breathing pulmonary acinar airways. J Vis Exp 2016 [Epub ahead of print]; DOI: 10.3791/53588.

112. Huh D, Leslie DC, Matthews BD, et al. A human disease model of drug toxicity-induced pulmonary edema in a lungon-a-chip microdevice. Sci Transl Med 2012:4;159ra147.

113. Benam KH, Novak $R$, Nawroth $J$, et al. Matchedcomparative modeling of normal and diseased human air- way responses using a microengineered breathing lung chip. Cell Syst 2016:3;456-466.e4.

114. Hassell BA, Goyal G, Lee E, et al. Human organ chip models recapitulate orthotopic lung cancer growth, therapeutic responses, and tumor dormancy in vitro. Cell Rep 2017:21; 508-516.

115. Barkal LJ, Procknow CL, Alvarez-Garcia YR, et al. Microbial volatile communication in human organotypic lung models. Nat Commun 2017:8;1770.

116. Benam KH, Villenave R, Lucchesi C, et al. Small airwayon-a-chip enables analysis of human lung inflammation and drug responses in vitro. Nat Methods 2016:13;151-157.

117. Xu J, Singhera GK, Dorscheid DR. Expression of surfactant protein $\mathrm{D}$ in airways of asthmatics and interleukin13 modulation of surfactant protein D in human models of airway epithelium. Respir Res 2015:16;26.

118. Koman PD, Mancuso P. Ozone exposure, cardiopulmonary health, and obesity: A substantive review. Chem Res Toxicol 2017:30;1384-1395.

119. Djuric-Filipovic I, Caminati M, Filipovic D, et al. Effects of specific allergen immunotherapy on biological markers and clinical parameters in asthmatic children: A controlled-real life study. Clin Mol Allergy 2017:15;7.

120. Caminati M, Duric-Filipovic I, Arasi S, et al. Respiratory allergies in childhood: Recent advances and future challenges. Pediatr Allergy Immunol 2015:26;702-710.

121. Lin C-S, Liu C-C, Yeh C-C, et al. Diabetes risks and outcomes in chronic obstructive pulmonary disease patients: Two nationwide population-based retrospective cohort studies. PLoS One 2017:12; e0181815.

122. Cau F, Pisu E, Gerosa C, et al. Interindividual variability in the expression of surfactant protein $\mathrm{A}$ and $\mathrm{B}$ in the human lung during development. Eur J Histochem 2016:60;2678.

123. Clark JG, Kim K-H, Basom RS, et al. Plasticity of airway epithelial cell transcriptome in response to flagellin. PLoS One 2015:10; $\mathrm{e} 0115486$.

124. Boei JJWA, Vermeulen S, Klein B, et al. Xenobiotic metabolism in differentiated human bronchial epithelial cells. Arch Toxicol 2017:91;2093-2105.

125. Ludwig N, Leidinger P, Becker K, et al. Distribution of miRNA expression across human tissues. Nucleic Acids Res 2016:44;3865-3877.

126. Molina-Pinelo S, Gutierrez G, Pastor MD, et al. MicroRNAdependent regulation of transcription in non-small cell lung cancer. PLoS One 2014:9; e90524.

127. Spitz MR, Wu X, Wang Y, et al. Modulation of nucleotide excision repair capacity by XPD polymorphisms in lung cancer patients. Cancer Res 2001:61;1354-1357.

128. Wang L-E, Gorlova OY, Ying J, et al. Genome-wide association study reveals novel genetic determinants of DNA repair capacity in lung cancer. Cancer Res 2013:73;256-264.

129. Xing D, Qi J, Tan W, et al. [Association of genetic polymorphisms in the DNA repair gene XPD with risk of lung and esophageal cancer in a Chinese population in Beijing]. Zhonghua Yi Xue Yi Chuan Xue Za Zhi 2003:20;35-38.

130. Walker DG, Whetzel AM, Serrano G, et al. Characterization of RNA isolated from eighteen different human tissues: Results from a rapid human autopsy program. Cell Tissue Bank 2016:17;361-375.

131. Thomas SM, Kagan C, Pavlovic BJ, et al. Reprogramming LCLs to iPSCs results in recovery of donor-specific gene expression signature. PLoS Genet 2015:11;e1005216.

132. Park S, Gianotti-Sommer A, Molina-Estevez FJ, et al. A comprehensive, ethnically diverse library of sickle cell 
disease-specific induced pluripotent stem cells. Stem Cell Reports 2017:8;1076-1085.

133. Huang SXL, Islam MN, O’Neill J, et al. Efficient generation of lung and airway epithelial cells from human pluripotent stem cells. Nat Biotechnol 2014:32;84-91.

134. Wong AP, Chin S, Xia S, et al. Efficient generation of functional CFTR-expressing airway epithelial cells from human pluripotent stem cells. Nat Protoc 2015:10;363-381.

135. Firth AL, Dargitz CT, Qualls SJ, et al. Generation of multiciliated cells in functional airway epithelia from human induced pluripotent stem cells. Proc Natl Acad Sci U S A 2014:111;E1723-E1730.

136. Ghaedi M, Niklason LE. Human pluripotent stem cells (iPSC) generation, culture, and differentiation to lung progenitor cells. Methods Mol Biol 2016 [Epub ahead of print]; DOI: 10.1007/7651_2016_11.

137. Asiedu MK, Barron M, Aubry MC, et al. Patient- and cell type-specific heterogeneity of metformin response. Basic Clin Pharmacol Toxicol 2018:122;214-222.

138. Gonzalez F, Zhu Z, Shi Z-D, et al. An iCRISPR platform for rapid, multiplexable, and inducible genome editing in human pluripotent stem cells. Cell Stem Cell 2014:15; 215-226.

139. Merkert S, Martin U. Site-specific genome engineering in human pluripotent stem cells. Int J Mol Sci 2016:17;pii: E1000.

140. Gupta RM, Musunuru K. Mapping novel pathways in cardiovascular disease using eQTL data: The past, present, and future of gene expression analysis. Front Genet 2012:3;232.

141. Skamagki M, Correia C, Yeung P, et al. ZSCAN10 expression corrects the genomic instability of iPSCs from aged donors. Nat Cell Biol 2017:19;1037-1048.

142. Fazzina R, Iudicone P, Fioravanti D, et al. Potency testing of mesenchymal stromal cell growth expanded in human platelet lysate from different human tissues. Stem Cell Res Ther 2016:7;122.

143. Ahmed E, Sansac C, Assou S, et al. Lung development, regeneration and plasticity: From disease physiopathology to drug design using induced pluripotent stem cells. Pharmacol Ther 2018:183;58-77.

144. Fedak KM, Bernal A, Capshaw ZA, et al. Applying the Bradford Hill criteria in the 21st century: How data integration has changed causal inference in molecular epidemiology. Emerg Themes Epidemiol 2015:12;14.

145. Ferdowsian HR, Beck N. Ethical and scientific considerations regarding animal testing and research. PLoS One 2011:6;e24059.
146. Rijal G, Li W. A versatile 3D tissue matrix scaffold system for tumor modeling and drug screening. Sci Adv 2017:3; e1700764.

147. Singh M, Close DA, Mukundan S, et al. Production of uniform 3D microtumors in hydrogel microwell arrays for measurement of viability, morphology, and signaling pathway activation. Assay Drug Dev Technol 2015:13; 570-583.

148. Goyak KMO, Johnson MC, Strom SC, et al. Expression profiling of interindividual variability following xenobiotic exposures in primary human hepatocyte cultures. Toxicol Appl Pharmacol 2008:231;216-224.

149. Grassi MA, Rao V, Winkler KP, et al. Genetic variation is the major determinant of individual differences in leukocyte endothelial adhesion. PLoS One 2014:9; e87883.

150. Sakamoto A, Matsumaru T, Yamamura N, et al. Quantitative expression of human drug transporter proteins in lung tissues: Analysis of regional, gender, and interindividual differences by liquid chromatography-tandem mass spectrometry. J Pharm Sci 2013:102;3395-3406.

151. Mitchell KA, Zingone A, Toulabi L, et al. Comparative transcriptome profiling reveals coding and noncoding RNA differences in NSCLC from African Americans and European Americans. Clin Cancer Res 2017:23; $7412-7425$.

152. Mezheyeuski A, Bergsland CH, Backman M, et al. Multispectral imaging for quantitative and compartment-specific immune infiltrates reveals distinct immune profiles that classify lung cancer patients. J Pathol 2017 [Epub ahead of print]; DOI: 10.1002/path.5026.

153. Jiang $\mathrm{C}, \mathrm{Hu} \mathrm{X}$, Alattar M, et al. miRNA expression profiles associated with diagnosis and prognosis in lung cancer. Expert Rev Anticancer Ther 2014:14;453-461.

154. Fleck RA, Romero-Steiner S, Nahm MH. Use of HL-60 cell line to measure opsonic capacity of pneumococcal antibodies. Clin Diagn Lab Immunol 2005:12;19-27.

Address correspondence to:

Dr. Shaun D. McCullough

National Health and Environmental Effects Research Laboratory

US Environmental Protection Agency 104 Mason Farm Road Chapel Hill, NC 27514

E-mail: mccullough.shaun@epa.gov 